\title{
ANALIZA TAČNOSTI IMPEDANTNE METODE PRI VARIJACIJI PARAMETARA DISTRIBUTIVNE MREŽE
}

\section{ACCURACY ANALYSIS OF THE IMPEDANCE METHOD IN VARIATION OF PARAMETERS OF DISTRIBUTION NETWORK}

\begin{abstract}
Oblast - ELEKTROTEHNIKA I RAČUNARSTVO
Kratak sadržaj - U ovom radu razmatran je proračun kratkih spojeva $i$ lokacije kvara primjenom impedantne metode u distributivnim mrežama, priložene teorijske osnove o istim, a takođe definisan $i$ algoritam pomoću koga se dolazi do rješenja zadatog problema. Analiziran je uticaj dužine sekcije na tačnost proračuna, zatim preciznost proračuna kod kvarova na početnim sekcijama izvoda, kao i uticaj uzemljenja transformatora. Obrađen je $i$ uticaj dodatih generatora na pojedinim izvodima na rezultate proračuna. Svi proračuni su realizovani pomoću programa koji je za potrebe ovog rada razvijen $u$ programskom jeziku $C++$. Dobijeni rezultati su prikazani tabelarno i izvršena je njihova analiza.
\end{abstract}

Danojla Ilić, Fakultet tehničkih nauka, Novi Sad transformatore i vodove. algoritam. mane.
Ključne reči: Distributivna mreža, Impedantna metoda, Lokacija kvara

\begin{abstract}
This document presents the calculation of short circuits and fault locations using the impedancebase method in distribution networks, the attached theoretical basis for the same, and also defines the algorithm by which to solve the given problem. The influence of the section length on the accuracy of the calculation, then the accuracy of the calculation in case of failures on the initial sections of the terminal, as well as the influence of the grounding of the transformer were analyzed. The influence of added generators on individual leads on the calculation results is also treated. All calculations are done by using a program specially designed for the purposes of this thesis, developed in the $C++$ programming language. The obtained results are presented in the form of tables and they were appropriately analyzed.
\end{abstract}

Keywords: Distribution network, Impedance-based method, Fault location

\section{UVOD}

Elektroenergetski sistem je tehnički sistem čiji je osnovni zadatak da obezbjedi pouzdano i kvalitetno napajanje električnom energijom.

Elektroenergetski sistemi su konstantno izloženi kvarovima, što utiče na njihovu pouzdanost, sigurnost $\mathrm{i}$ kvalitet električne energije.

\section{NAPOMENA:}

Ovaj rad proistekao je iz master rada čiji mentor je bio dr Duško Bekut, red. prof.
U ovom radu, analizirana je tačnost impedantnog algoritma za procenu lokacije kvarova, uslijed promjene parametara distributivne mreže [1-5].

U drugoj glavi ukratko su opisani elementi elektroenergetskog sistema, sa posebnim osvrtom na generatore,

U trećoj glavi su priložene teorijske osnove o kratkim spojevima i detaljno jeopisan admitantno-impedantni

U četvrtoj glavi opisani su algoritmi za metodologije koje se koriste za procjenu mjesta kvara, njihove prednosti i

Peta glava opisuje primjenu impedantnog algoritma na izabranoj test mreži. U cilju detaljnije analize vršena je promjena parametara distributivne mreže i analiziran uticaj istih na tačnost proračuna.

Poslednje dve glave su zaključak i literatura.

\section{ELEMENTI ELEKTROENERGETSKIH SISTEMA}

Elementi elektroenergetskih sistema su generatori, transformatori, vodovi i potrošači. U ovoj glavi opisani su generatori, transformatori i vodovi.

\subsection{Elektrane}

Podsistem proizvodnje sastoji se od elektrana koje predstavljaju osnovne izvore električne energije, koji treba da u svakom trenutku zadovolje potrošnju sistema, kao i da obezbjede neophodnu rezervu kapaciteta za pokrivanje iznenadnih promjena opterećenja i neplaniranih ispada proizvodnih kapaciteta.

\subsubsection{Generatori}

Pored elektrana podsistem proizvodnje čine i generatori koji se priključuju na distributivne mreže $(35 \mathrm{kV}, 20 \mathrm{kV}$ i $10 \mathrm{kV})$ - distributivni generatori (DG). Takođe, generatori priključeni na niskonaponsku mrežu dio su podsistema proizvodnje - DG u okviru samih potrošača. U poslednje vrijeme oni postaju sve atraktivniji i pomoću njih je moguće rasteretiti kapacitete osnovne proizvodnje elektrana.

Problemi koji se javljaju priključenjem DG na mrežu su ostrvski rad, skraćenje dosega releja i problem selektivnosti zaštite.

\subsection{Transformatori}

Transformatori električnu energiju jednog napona i struje pretvaraju u električnu energiju nekog drugog napona i struje. Njihov rad se zasniva na elektromagnetnoj indukciji. 
Na osnovu eksperimenta kratkog spoja i praznog hoda, određuju se parmetri pogonskih šema trofaznih dvonamotajnih transformatora.

Ako su namotaji trasformatora tako povezani i priključci izvedeni i njegovo priključenje u elektroenergetski sistem u simetričnom režimu ne poremeti simetriju režima, tada se kaže da taj transformator ima određenu spregu.

Sprega se označava kombinacijom slova i brojeva, gdje je prvom slovo veliko i predstavlja način povezivanja visokonaponskog (VN) namotaja, a drugo slovo je malo $i$ predstavlja način povezivanja niskonaponskog (NN) namotaja.

Sprežni broj čine brojevi od 0 do 11 , gdje se povezivanjem namotaja $\mathrm{VN}$ i NN na isti način dobijaju sprege sa parnim, a povezivanjem na različit sprege sa neparnim sprežnim brojevima.

\subsection{Trofazni vodovi}

Sekcije vodova mogu biti nadzemne i podzemne sa izolovanim i neizolovanim provodnicima. U distributivnoj mreži podzemni vodovi su sa izolovanim provodnicima, a nadzemni su sa neizolovanim provodnicima. Upotreba jednih ili drugih zavisi od više faktora kao što su potrebna pouzdanost napajanja, razvijenost sredine i drugi.

\section{KRATKI SPOJEVI}

Pod kratkim spojem se podrazumijeva direktan spoj između tačaka koje se u normalnim uslovima nalaze na različitim potencijalima, pri čemu vrijednosti struja kratkog spoja znatno premašuju nominalne.

\subsection{Impedantno - admitantni algoritam}

Distributivna mreža se dekomponuje na kolo sa režimom prije kvara i fiktivno kolo.

Proračun u fiktivnom kolu počinje učitavanjem podataka o distributivnoj mreži (DM), numeracijom grana i čvorova po lejerima, a zatim i računanjem dva ekvivalenta:

- ekvivalenta mreže do krajeva i

- ekvivalenta mreže do korijena mreže.

Sledeći korak je proračun režima sa ratkim spojem na mjestu kratkog spoja, gdje je potrebno odrediti tip i mjesto istog.

Za zadati tip kratkog spoja vrijednosti simetričnih komponenti struja na mjestu kratkog spoja su funkcija napona na mjestu kratkog spoja prije kratkog spoja - koji se dobija se pri proračunu tokova snaga i odgovarajuće Thevenin-ove impedanse koja se računa na osnovu ekvivalentne impedanse.

Na slici 1 prikazan je globalni blok dijagram admitantno impedantnog algoritma za model mreže.

\section{PROCJENA MJESTA KVARA}

Da bi se kvar uspješno eliminisao, neophodno ga je prvo locirati, a zatim i izolovati od ostalog dijela DM, a nakon toga i izvršiti restauraciju napajanja.

\subsection{Metodologije za procjenu mjesta kvara}

Lokacija kvara zahtijeva određeno vrijeme u toku koga potrošači ostaju bez napona.

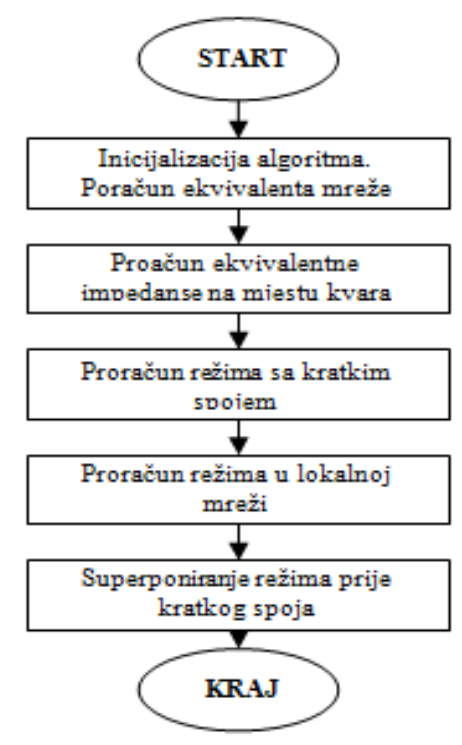

Slika 1. - Globalni blok dijagram admitantnoimpedantnog algoritma

U otkrivanju dionice sa kvarom značajnu ulogu imaju detektori kvara na osnovu kojih se saznaje kroz koje dionice je protekla struja kvara. Postupak se izvodi kroz više iteracija od početka izvoda ka kraju. Ako je detektor aktivan, to znači da je kroz to mesto ,prošla“ struja kvara. Kada se pronađe stanica u kojoj je detektor deaktiviran, proces se zaustavlja. Kvar se nalazi na dionici između stanice sa detektorom koji je odreagovao i deaktiviranim detektorom.

Neke od metoda lokacije kvara bazirane su na praktičnim iskustvima, kao što su utvrđivanje okoline kvara na osnovu većeg broja poziva potrošača koji se nalaze $u$ relativnoj blizini.

Postupak metode polovljenja nije potreban ako je distributivna mreža opremljena SCADA nadgledanjem i ako su svi potrebni uređaji povezani sa SCADA upravljanjem.

Najkvalitetnije procjene se dobijaju kombinovanjem upotrebe računarske metode i brze mjerne jedinice. To je slučaj kod strujnog i impedantnog algoritma.

\subsubsection{Strujni algoritam}

Strujni algoritam zasnovan je na mjerenju struje. Postupak počinje određivanjem izvoda i tipa kratkog spoja, a zatim se ustanovljeni tip kvara (u ovom radu jednopolni kvar= simulira na sabirnicama sa kojih polazi izvod sa kvarom, a onda i na sabirnicama na krajevima svih dionica tog izvoda.

Za svako mjesto kvara računa se vrijednost struje koja bi se dobila mjerenjem brzom mjernom jedinicom, formirajući na taj način uređen par vrijednosti struja koje odgovaraju vrijednostima struja za kratki spoj na početku i na kraju date dionice.

Nakon toga se upoređuju izračunate vrijednosti struje sa mjerenim vrijednostima, za sve dionice. Za moguće dionice sa kvarom se uzimaju one kod kojih je mjerena vrijednost struje manja ili jednaka od prve, a istovremeno veća ili jednaka od druge vrijednosti uređenog para vrijednosti struja. Na slici 2. prikazan je globalni blok dijagram strujnog algoritma. 


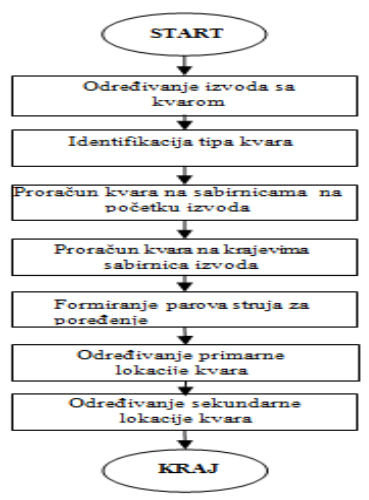

Slika 2. - Globalni blok dijagram strujnog algoritma

\subsubsection{Impedantni algoritam}

Impedantna metoda lokacije kvara počinje određivanjem ekvivalentne impedanse direktnog i nultog redoslijeda na osnovu režima prije kvara, a zatim se nakon detektovanja kvara računa ekvivalentna impedansa petlje kvara koja zavisi od tipa kvara. Na osnovu date impedanse se locira kvar.

$\mathrm{Na}$ osnovu izmjerenih vrijednosti napona i struje, računa se impedansa između mjerne jedinice i mjesta kvara. Koji tip kvara je u pitanju, saznaje se na osnovu mjerenja, identifikacijom faza sa povećanim vrijednostima struje. $\mathrm{Na}$ kom izvodu se dogodio kvar se saznaje na osnovu prorade releja. Distantni relej mjeri impedansu direktnog redoslijeda.

Primarne dionice sa kvarom su one kod kojih je imaginarni dio impedanse $Z_{\mathrm{ff}}$ istovremeno manji ili jednak od imaginarnog dijela impedanse $Z_{\mathrm{ff}}$, a veći od imaginarnog dijela impedanse $Z_{\mathrm{ff}}$, tj za koje važi sledeća relacija:

$$
\operatorname{Im}\left\{Z_{f f 1}\right\} \leq \operatorname{Im}\left\{Z_{f f}\right\} \leq \operatorname{Im}\left\{Z_{f f 2}\right\} \ldots \ldots \ldots \ldots \ldots . .
$$

gdje su $Z_{\mathrm{ff} 1}$ i $Z_{\mathrm{ff2}}$ impedanse dionice na početku i kraju, a $Z_{\mathrm{ff}}$ izračunata impedansa.

Uzimajući u obzir grešku mjerenja procjenjuju se i moguće dionice koje predstavljaju sekundarne lokacije kvara. Na slici 3. prikazan je globalni blok dijagram impedantnog algoritma.

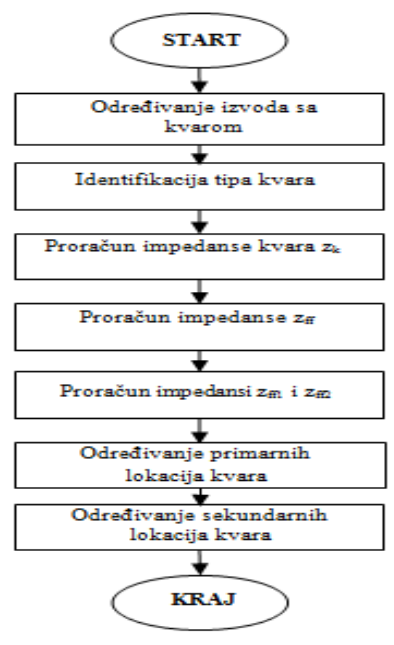

Slika 3. - Globalni blok dijagram impedantnog algoritma

\section{PRIMJENA IMPEDANTNOG ALGORITMA}

U ovoj glavi je dat primjer proračuna lokacije određenog tipa kratkog spoja primjenom impedantnog algoritma na test mreži prikazanoj na slici 4 .

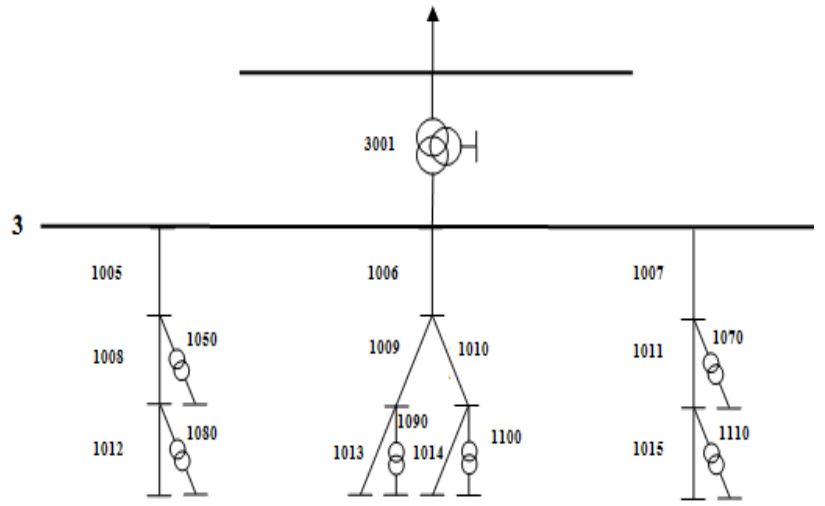

Slika 4. - Jednostavna distributivna mreža

Svi proračuni su napravljeni sa podrškom razvijenom u programskom jeziku $\mathrm{C}++$.

$\mathrm{Na}$ ovoj mreži potrebno je pronaći lokaciju kvara impedantnom metodom. Zatim treba simulacijom kvara na određenim sekcijama i promjenom određenih parametara, analizirati preciznost metode: kod veoma kratkih sekcija, početnih sekcija, kao i uticaj uzemljenja transformatora na tačnost proračuna. Na kraju je potrebno dodati generator na drugi kraj mreže i analizirati njegov uticaj na tačnost određivanja mjesta kvara.

Ulazni podaci o jednostavnoj DM smješteni su u odgovarajućim ulaznim fajlovima, a vrednosti su preuzete iz [1].

Prije početka proračuna potrebno je normalizovati parametre DM. Nakon toga se numerišu grane i čvorovi po lejerima i DM se priprema za tretman kratkih spojeva.

\subsection{Uticaj dužine sekcija na tačnost proračuna}

U ovom primjeru se sekciji 1008 mjenja inicijalna dužina u svrhu analize tačnosti, pa se zadaju redom dužine 100 $\mathrm{m}, 50 \mathrm{~m}, 20 \mathrm{~m}$ i $10 \mathrm{~m}$, a zatim se analizira preciznost proračuna ukoliko se kvar desi na $20 \%, 40 \%, 60 \%$ i na $80 \%$ dužine sekcije. Tačnost detektovanja deonice izvoda sa kvarom pri apsolutno tačnim mjerenjima prikazana je u tabeli 1, gdje oznaka $\mathrm{T}^{1008}$ pokazuje da je tačno detektovana dionica sa kvarom, a superskript 1008 predstavlja oznaku dionice, dok analogno tome, $\mathrm{npr} \mathrm{N}^{1012}$ pokazuje da nije detektovana tačna dionica sa kvarom, već dionica 1012.

Tabela 1. - Tačnost detektovanja dionice sa kvarom pri različitim dužinama dionice i mjesta kvara za apsolutnu tačnost mjerenja

\begin{tabular}{|c|c|c|c|c|c|}
\hline & $1[\mathrm{~km}]$ & $0.1[\mathrm{~km}]$ & $0.05[\mathrm{~km}]$ & $0.02[\mathrm{~km}]$ & $0.01[\mathrm{~km}]$ \\
\hline 0.2 & $\mathrm{~T}^{1008}$ & $\mathrm{~T}^{1008}$ & $\mathrm{~T}^{1008}$ & $\mathrm{~T}^{1008}$ & $\mathrm{~T}^{1008}$ \\
\hline 0.4 & $\mathrm{~T}^{1008}$ & $\mathrm{~T}^{1008}$ & $\mathrm{~T}^{1008}$ & $\mathrm{~T}^{1008}$ & $\mathrm{~T}^{1008}$ \\
\hline 0.6 & $\mathrm{~T}^{1008}$ & $\mathrm{~T}^{1008}$ & $\mathrm{~T}^{1008}$ & $\mathrm{~T}^{1008}$ & $\mathrm{~T}^{1008}$ \\
\hline 0.8 & $\mathrm{~T}^{1008}$ & $\mathrm{~T}^{1008}$ & $\mathrm{~T}^{1008}$ & $\mathrm{~T}^{1008}$ & $\mathrm{~T}^{1008}$ \\
\hline
\end{tabular}

Međutim, ako se uzme u obzir greška mjerenja od $+1 \%$ dobijaju se rezultati prikazani u tabeli 2 .

Što je dionica kraća, a mjesto kvara udaljenije od početka dionice, to je veća nepreciznost detektovanja lokacije kvara. 
Tabela 2. - Tačnost detektovanja dionice sa kvarom pri različitim dužininama dionice i mjesta kvara uzimajući $u$ obzir grešku mjerenja od $+1 \%$

\begin{tabular}{|c|c|c|c|c|c|}
\hline & $1[\mathrm{~km}]$ & $0.1[\mathrm{~km}]$ & $0.05[\mathrm{~km}]$ & $0.02[\mathrm{~km}]$ & $0.01[\mathrm{~km}]$ \\
\hline 0.2 & $\mathrm{~T}^{1008}$ & $\mathrm{~T}^{1008}$ & $\mathrm{~T}^{1008}$ & $\mathrm{~T}^{1008}$ & $\mathrm{~N}^{1012}$ \\
\hline 0.4 & $\mathrm{~T}^{1008}$ & $\mathrm{~T}^{1008}$ & $\mathrm{~T}^{1008}$ & $\mathrm{~T}^{1008}$ & $\mathrm{~N}^{1012}$ \\
\hline 0.6 & $\mathrm{~T}^{1008}$ & $\mathrm{~T}^{1008}$ & $\mathrm{~T}^{1008}$ & $\mathrm{~N}^{1012}$ & $\mathrm{~N}^{1012}$ \\
\hline 0.8 & $\mathrm{~T}^{1008}$ & $\mathrm{~T}^{1008}$ & $\mathrm{~N}^{1012}$ & $\mathrm{~N}^{1012}$ & $\mathrm{~N}^{1012}$ \\
\hline
\end{tabular}

\subsection{Preciznost proračuna kvarova na početnim sekcijama}

U ovom dijelu simulira se kvar na sekcijama 1005, 1006 i 1007. Pogrešna dionica sa kvarom, u ovom slučaju, detektuje se samo kada se mjesto kvara nalazi pri kraju dionice i uz velike greške mjerenja, što je i prikazano u tabeli 3. Simulirani su kvarovi na sekciji 1005 (čija je dužina $1 \mathrm{~km})$ i to na $90 \%, 93 \%, 96 \%$ i $99 \%$ dužine sekcije, uzimajući u obzir da je greška mjerenja $+2 \%$, $+4 \%,+6 \%,+8 \%$ i $+10 \%$.

Tabela 3 - Tačnost proračuna na početnim sekcijama izvoda uzimajući u obzir grešku mjerenja i udaljenost mjesta kvara

\begin{tabular}{|c|c|c|c|c|c|}
\hline & 1.02 & 1.04 & 1.06 & 1.08 & 1.10 \\
\hline 0.90 & $\mathrm{~T}^{1005}$ & $\mathrm{~T}^{1005}$ & $\mathrm{~T}^{1005}$ & $\mathrm{~T}^{1005}$ & $\mathrm{~T}^{1005}$ \\
\hline 0.93 & $\mathrm{~T}^{1005}$ & $\mathrm{~T}^{1005}$ & $\mathrm{~T}^{1005}$ & $\mathrm{~N}^{1008}$ & $\mathrm{~N}^{1008}$ \\
\hline 0.96 & $\mathrm{~T}^{1005}$ & $\mathrm{~T}^{1005}$ & $\mathrm{~N}^{1008}$ & $\mathrm{~N}^{1008}$ & $\mathrm{~N}^{1008}$ \\
\hline 0.99 & $\mathrm{~N}^{1008}$ & $\mathrm{~N}^{1008}$ & $\mathrm{~N}^{1008}$ & $\mathrm{~N}^{1008}$ & $\mathrm{~N}^{1008}$ \\
\hline
\end{tabular}

\subsection{Uticaj uzemljenja transformatora na tačnost proračuna}

Vrijednost rezistanse otpornika $R_{u z}$ preko koga je transformator uzemljen je sada je $40 \Omega$ umjesto $0 \Omega$. Pokretanjem proračuna detektuje se tačna dionica kvara. Povećanjem $R_{u z}$ na $200 \Omega$, takođe se dobijaju tačni rezultati, što znači da povećanje rezistanse ne utiče na tačnost proračuna.

\subsection{Uticaj račvanja dionica na tačnost proračuna}

Kvar se simulira na sekciji 1009. Ukoliko su svi parametri inicijalni, a mjesto kvara na 80\% dužine dionice, pokretanjem proračuna dobijaju se dva moguća rješenja, sekcije 1009 i 1014.

To znači da u slučaju račvanja impedantni algoritam nije dovoljno precizan, pa je potrebna primjena i detektora kvara koji se stavlja na račve i određuje na kojoj strani se nalazi kvar.

\subsection{Dodavanje generatora na krajevima test mreže i njegov uticaj na proračun}

U test mrežu se dodaju generatori u čvorove 20, 6 i 14. Analiziraju se različiti slučajevi, prva tri kada je aktivan po jedan generator i četvrti kada su aktivna sva tri generatora. Analizira se kvar na sekciji 1008 na 20\%, $40 \%, 60 \%$ i $80 \%$ dužine sekcije. Rezultati su u tabeli 4 . iz koje se vidi da i kada je aktivan jedan i kada su aktivna sva tri generatora detektuje se tačna dionica.
Tabela 4. Tačnost detektovanja dionice sa kvarom pri različitim dužininama dionice u slučaju dodavanja generatora u izabranim čvorovima

\begin{tabular}{|c|c|c|c|c|}
\hline & $\begin{array}{c}\text { Aktivan } \\
\text { generator u } \\
\text { ćvoru } 20\end{array}$ & $\begin{array}{c}\text { Aktivan } \\
\text { generator u } \\
\text { čvoru 6 }\end{array}$ & $\begin{array}{c}\text { Aktivan } \\
\text { generator u } \\
\text { čvoru 14 }\end{array}$ & $\begin{array}{c}\text { Aktivna sva tri } \\
\text { generatora }\end{array}$ \\
\hline 0.2 & $\mathrm{~T}^{1008}$ & $\mathrm{~T}^{1008}$ & $\mathrm{~T}^{1008}$ & $\mathrm{~T}^{1008}$ \\
\hline 0.4 & $\mathrm{~T}^{1008}$ & $\mathrm{~T}^{1008}$ & $\mathrm{~T}^{1008}$ & $\mathrm{~T}^{1008}$ \\
\hline 0.6 & $\mathrm{~T}^{1008}$ & $\mathrm{~T}^{1008}$ & $\mathrm{~T}^{1008}$ & $\mathrm{~T}^{1008}$ \\
\hline 0.8 & $\mathrm{~T}^{1008}$ & $\mathrm{~T}^{1008}$ & $\mathrm{~T}^{1008}$ & $\mathrm{~T}^{1008}$ \\
\hline
\end{tabular}

\section{ZAKLJUČAK}

Cilj ovog rada bio je da se uradi analiza tačnosti primjene impedantne metode u lokaciji kvarova, kao i koliko na to utiču pojedini parametri. Da bi se to moglo realizovati, bilo je neophodno na izabranom primeru mreže, korišćenjem impedantno-admitantnog algoritma analizirati tačnost impedantne metode za lociranje kvara na različitim primerima.

Do grešaka dolazi najviše uslijed grešaka mjerenja, na početnim sekcijama izvoda i to ako je mjesto kvara blizu kraja sekcije. Takođe, kod veoma kratkih sekcija, što je kvar udaljeniji, uslijed pozitivnih grešaka mjerenja, dolazi do pogrešnog detektovanja dionica, dok za negativne greške mjerenja važi suprotno. Pokazano je da povećanje vrijednosti rezistanse otpornika, preko koga je transformator uzemljen, ne utiče na preciznost proračuna.

Ustanovljeno je da račvanje rezultuje sa više mogućih rješenja, gdje su jednake šanse za izbor ciljne dionice, pa se taj problem može riješiti upotrebom detektora kvara. $\mathrm{Na}$ kraju je utvrđeno da i dodavanje generatora na krajevima mreže ne utiče na proračun, što je bio očekivan rezultat.

\section{LITERATURA}

[1] Dragan Popović, Duško Bekut, Valentina Dabić: „Specijalizovani DMS algoritmi““, DMS Group, Novi Sad, 2011.

[2] Vladimir Strezoski: „Analiza elektroenergetskih sistema“", Fakultet tehničkih nauka, Novi Sad, 2012.

[3] M. D. Nimrihter, P. N. Đapić: „Proračuni u distributivnim električnim sistemima“, Fakultet Tehničkih nauka, Novi Sad, 2008.

[4] Milan S. Ćalović, Predrag Č. Stefanov, Andrija T. Sarić: „Eksploatacija elektroenergetskih sistema u uslovima slobodnog tržišta“, Tehnički fakultet, Čačak.

[5] https://www.researchgate.net /publication/337857354 UTICAJ_DISTRIBUIRANIH_GENERATORA_NA_ DI-STRIBUTIVNU_MREZU

\section{Kratka biografija:}

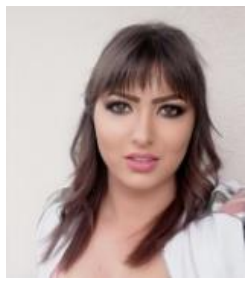

Danojla Ilić rođena je u Bileći 1993. god. Osnovne studije završila je na Fakultetu tehničkih nauka 2017. god iz oblasti Elektrotehnike i računarstva, smjer Elektroenergetski sistemi. Master studije upisala je 2017. god na istom fakultetu smjer Elektroenergetika - Elektroenergetski sistemi. 